\title{
Comentario al libro "Luchar por la justicia al viento del espíritu. Autobiografía y esbozo de historia de mi generación”, de Juan Hernández Pico
}

\section{Josefina Vijil}

Porque vivimos a golpes, porque apenas si nos dejan decir que somos quien somos, nuestros cantares no pueden ser sin pecado un adorno.

Estamos tocando el fondo.

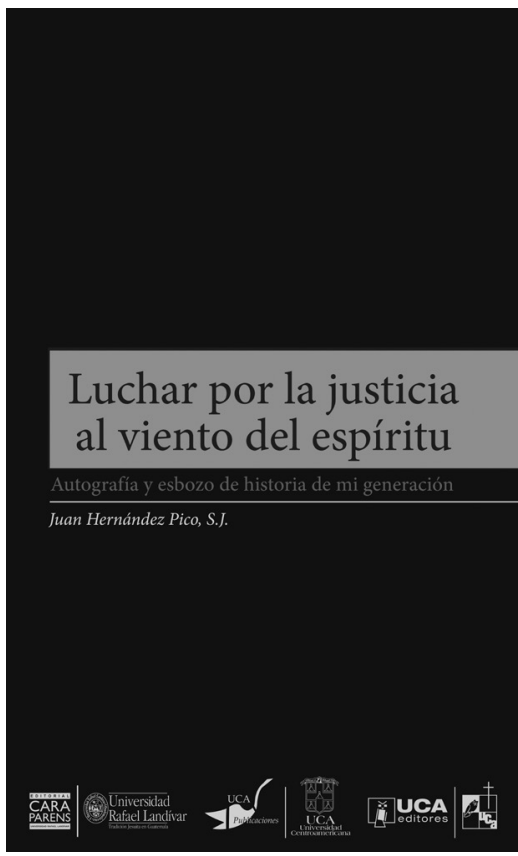

Maldigo la poesía concebida como un lujo cultural por los neutrales que, lavándose las manos, se desentienden y evaden.

Maldigo la poesía de quien no toma partido hasta mancharse.

Hago mías las faltas. Siento en mi a cuantos sufren y canto respirando.

Gabriel Celaya "La poesía es un arma cargada de futuro"

Los versos de Celaya convertidos en canción y que Piquito incluyó textualmente en el libro resumen su vida y el quehacer del sector de la Compañía de Jesús en la región de la que también nos habla. "Maldigo la poesía de quien

Investigadora, experta en educación. Centro de Investigación y Acción Educativa Social (CIASES), Managua. 
no toma partido hasta mancharse" verbalizan lo que tantas personas sentimos: nuestra ética, nuestros principios exigen un compromiso con diferentes causas, no exento de riesgos: de equivocarnos, de apoyar a quien no debimos, de analizar superficialmente una situación, de tomar decisiones incorrectas. Pero el riesgo de "mancharse" no es excusa para no comprometerse.

Piquito explica: "la motivación profunda y pública de nuestra tarea social era, en nuestra conciencia, la fe, la esperanza y el amor cristiano que habiamos recibido en el Evangelio. Y sobre todo el conocimiento de Jesucristo, el amor a él y el seguimiento a él". Esto a pesar de afrontar "el desafío de afirmar y confesar que las opciones del amor a los pobres son auténticas, incluso si Dios no existiera". Afirma, usando una frase de Nicolás Berdiaeff, "el hambre mía es un problema material, pero el hambre de mi prójimo es un problema espiritual, porque es un problema de solidaridad". Por ello tomaron decisiones difíciles asumiendo los riegos "sin dudar ni poder dudar".

Asumo que Piquito me propuso que participara de la presentación del libro como representante de mi papá, quien estaría encantado. No soy experta en nada de lo que trata el libro, mi padre en cambio fue un cristiano comprometido con la Revolución. Luego de su muerte algunas personas intentaron cuestionar su compromiso calificándolo de "ingenuo" y de haber sido manipulado políticamente.

Mi hermano Felix escribió un artículo reflexionando sobre esto y en uno de sus párrafos decía, a propósito de todos cuantos fueron parte del grupo de "Cristianos por la Revolución": "Su compromiso no fue ingenuo. Sabian que podian equivocarse, que en el camino encontrarían obstáculos, y se los encontraron. No por falta de reflexión o de pensamiento crítico y profundo. Lo hicieron porque a pesar de los riesgos, sintieron el llamado de Dios. Ese llamado les impidió quedarse callados y al margen de la historia".

Como no he presentado muchos libros, me documenté acerca de qué hay que decir cuando uno lo hace. Lo que todas las fuentes recomiendan es dar a conocer el contenido del libro a una audiencia y recomendar su lectura. Bien, me encantó el libro y disfruté su lectura. Lo leí en vacaciones, periodo que siempre reservo para leer varias novelas, y no lo consideré en ningún momento como trabajo. Me gustó su contenido, la manera en que está estructurado, la prosa. Les recomiendo que lo lean.

Quiero hablar ahora de la manera en que entendí e interpreté el libro y por qué considero que es una lectura obligatoria a través de cuatro ideas principales.

\section{Es un libro profundamente honesto que evidencia la coherencia de su vida y su compromiso.}

Además de abordar con honestidad y con todas sus letras los diferentes momentos y acciones de su vida, sin esconder lo que considera sus debilidades, se esfuerza por dar una explicación profunda de la teología de la liberación, y cómo el asumirla marcó la historia de la Compañía de Jesús en Centroamérica, a lo largo de tres décadas. Esa explicación nos permite concluir que, asumiendo esos principios, no era posible que los jesuitas de esta tendencia actuaran de otra manera que como lo hicieron en ese momento histórico, puesto que como él lo afirma: 
Con la teología de la liberación, se trata de una teología en la que Dios es mucho más que solo religioso, porque no le interesa una adoración, una reverencia o respeto que no sea a la vez lucha por la emancipación de sus hijos e hijas, los hermanos y hermanas de Jesús de Nazaret.

Es una teología que no entiende el poder de Dios como intervención directa en la historia, no como si fuera un dios tapagujeros, sino como la fuerza del Espíritu Santo que acompaña las tareas humanas de búsqueda del 'reino de dios y de la justicia'.

El mensaje de la teología de la liberación es que no se puede ser Iglesia sin ser Iglesia de los pobres y con los pobres; y que no se puede ser Iglesia que exija justicia y paz a la humanidad sin ser al mismo tiempo una comunidad austera y fraterna en medio de un mundo insolidario, codicioso y consumista.

En ese marco explica que Ellacuría hizo una formulación novedosa de las preguntas ignacianas que también marcaron el compromiso y las opciones de la Compañía, "¿Qué he hecho para bajar de la cruz a los crucificados de este mundo? ¿Qué hago hoy y qué puedo hacer?".

Resulta entonces de una gran coherencia cuando Piquito afirma que "lo anterior es lo que ha motivado mi vida invitándome a sentir, pensar y actuar (ojalá) servicial y asi liberadoramente al viento del espiritu”.

Agradezco su coherencia a lo largo de su vida. En otros países eso quizás no tendría que ser relevado, pero en Nicaragua tiene una importancia crucial puesto que luego del fin del periodo revolucionario, fácil y rápidamente se perdió el norte entre los revolucionarios. En unos cuantos años, y sin mediar ninguna reflexión, se nos olvidó la finalidad del compromiso de la revolución con la liberación, con los pobres. Que rápido nos acostumbramos al sálvese quien pueda, a la comodidad de la vida personal, segura, y no nos esforzamos por pensar, reposicionarnos y rescatar las finalidades últimas.

\section{El libro es una obra fundamental para Nicaragua: obliga a hacer una reflexión seria y rigurosa de su vida y de la realidad tal cual él la ve.}

Me siento agradecida por la explicación que Piquito se obliga a darnos, por intentar honestamente reconstruir la memoria para encontrar los fundamentos de esa tremenda historia que nos tocó vivir. También por el esfuerzo de hacer lo que nos falta en Nicaragua: reflexionar, analizar, sacar conclusiones, construir conocimientos. En un país y, creo, una región que no es prolija en eso, que se deja llevar por los vientos y la moda porque es más fácil, donde pocas personas se exigen el esfuerzo de un pensamiento riguroso: gracias por la oportunidad de leer este análisis.

Agradezco la profundidad, la seriedad, el rigor, el obligarse a teorizar, a construir categorías conceptuales que nos permitan aprehender la realidad que 
vivimos, y no usar las que existen a pesar de que la realidad no quepa en ellas.

Este esfuerzo lo hizo Piquito desde los años de revolución. Aquellos años en que usábamos la guerra como justificación para no pensar, no cuestionarnos y ni siquiera discutir, en donde era más fácil obedecer y cumplir sin cuestionar. Nos cuenta cómo él y un grupo de jesuitas comenzaron la tarea, que finalmente quedó inconclusa por decisión del Vaticano, de escribir un libro sobre marxismo desde Centroamérica.

Cuando nosotros estábamos en el activismo, ellos ya pensaban en la necesidad de contar con una teoría que permitiera analizar la realidad y actuar en consecuencia. Hace unos años Andrés Pérez Baltodano me pidió que hiciera algunas preguntas a uno de sus libros que, entre otras cosas, analiza y critica la manera en que se enseñó el marxismo en Nicaragua. Yo, que había sido formada durante mi licenciatura en "marxismo de manuales", le comenté a Andrés que sentía que el libro hablaba de mí, puesto que no conocí otra cosa que a Konstantinov. Si el libro de Piquito y los de los otros jesuitas hubiesen visto la luz quizás esta situación, en especial nuestra formación, las reflexiones y conocimientos que hubiésemos construido, nos habrían permitido ver la realidad de otra manera, y algunas cosas habrían sido diferentes.

En Nicaragua hay muchas deudas pendientes. Muchas personas opinan por ejemplo que mi generación, a la que le tocó desarrollar las urgentes tareas de la revolución: alfabetizar, levantar las cosechas, hacer proselitismo en universidades y barrios, y especialmente enfrentar la guerra, poner los muertos, es una "generación perdida" o pasmada que no se atreve a asumir liderazgos y que desesperadamente se ha aferrado al estudio, el trabajo y la familia, todo del orden de lo personal.

Es posible que eso sea cierto, pero eso es una consecuencia no una causa. La causa es que nunca terminamos de entender lo que pasó, no lo escudriñamos, no discutimos y especialmente no hicimos el duelo. Intentamos tirarlo al olvido y continuar. Sin embargo, no es posible continuar sin reconciliarnos con nuestro pasado, sin desarrollar una argumentación de lo que pasó y asumir un posicionamiento. Esto es una tarea pendiente. Agradezco a Piquito que adelante elementos de un análisis, intente interpretar, explicar. Que nos dé insumos para esa tarea pendiente.

Piquito no cae en anacronismos, no intenta explicar el pasado desde las realidades y categorías del presente, hace la reflexión a partir de las finalidades de la Revolución, y en esa tarea se autocritica utilizando las palabras de Ellacuría que les reclamaba que lo que hacían los jesuitas en Nicaragua era "apoyo público y crítica privada, cuando la crítica también debía ser pública".

Nunca razona con el hígado, como hacemos nosotros a veces, y nos dice que "a ese proceso no exento de errores, no le ha faltado compromiso con la causa de los pobres, le ha faltado eso sí oportunidad histórica de poder realizar su potencial en condiciones menos terriblemente adversas que las que les tocó sufrir".

También comparte cómo al momento de la derrota electoral hizo, a diferencia de cientistas sociales nicaragüenses que evadieron el debate, un análisis de la misma: "Confieso que no me toca hacer la autocrítica que en su momento espero que el FSLN y el pueblo revolucionario nicaragüense haga". Desgraciadamente esa reflexión y esa autocrítica nunca se hicieron, lo que probablemente está en la base del derrumbe ideológico y ético del FSLN. 


\section{Es un libro que plantea desafíos a la Compañía de Jesús y sus obras.}

A la luz del espíritu de este libro conviene que la UCA cuestione profundamente eso en lo que se ha convertido, y las causas a las que dedica sus esfuerzos. Piquito nos recuerda los ejes del discurso de los directivos de la UCA de San Salvador allá en el año 1970, transcribiendo el discurso que llevaron a Washington para pronunciarlo en la sede del BID (contrato de préstamo) en el que establecen lo que ha marcado la vida y el ser de esa universidad:

La forma específica con que la universidad debe ponerse al servicio de todos es dirigiendo su atención, sus esfuerzos y su funcionamiento universitario al estudio de aquellas estructuras que, por ser estructuras, condicionan, para bien o para mal la vida de todos los ciudadanos. Debe analizarlas críticamente, debe contribuir universitariamente a la denuncia y la destrucción de las injusticias, debe crear modelos nuevos para que la sociedad y el Estado puedan ponerlos en marcha. La universidad tiene que concientizar no con prácticas moralizantes, sino con estudios contundentes.

Además de reivindicar los desafíos que dejó César Jerez a la UCA de Nicaragua, también recuerda a los gigantes de la compañía, los mártires. Y es en ese contexto donde se vale debatir sobre ¿con qué se va a comprometer, qué va a hacer la UCA en el difícil y difuso panorama de la Nicaragua de hoy? Piquito nos da la palabra.

Frente a la tentación de quedar bien con el poder para no tener problemas -lo que conduce a la inmovilización y hace que personas e instituciones se autocensuren- Piquito nos recuerda que trabajar por la misión de la Compañía siempre nos enfrentará al poder: "No trabajaremos por la justicia sin que paguemos un precio".

\section{Es un libro que vislumbra respuestas a preguntas que no hemos formulado seriamente pero que flotan en el ambiente, que nos da esperanzas.}

A pesar de ser un libro ubicado en una etapa histórica convulsa en la que acontecieron hechos descorazonadores, como la derrota de la revolución en Nicaragua y el período de destrucción del movimiento revolucionario a causa de sus propios líderes, no es un libro pesimista, todo lo contrario, Piquito afirma que:

Con todas sus sombras, sentimos que nunca fue inútil ni en vano lo que aconteció en Nicaragua y otros países centroamericanos. Fue una indicación de un dedo apuntando hacia aquel mesianismo siempre necesario en la esforzada tarea de 'buscar el reino de Dios y su justicia'. 
Y acertadamente recuerda que "pueden haber desaparecido las utopías, pero subsiste el desafio amoroso y creyente de la esperanza". Nos interpela nuevamente y nos anima a la subversión al plantear que debemos acompañar ese desafío "con vigor en sus tortuosos caminos y en la investigación hacia sistemas alternativos nuevos".

También nos anima a trabajar para que el "inconformismo de los muertos" en las luchas revolucionarias de la región, provoque el de los vivos:

Atravesamos un momento de peligro, pero gracias a la crisis por la que está atravesando la idea de progreso, hay una oportunidad histórica, y es tan importante colocar al ángel de la historia en otra posición, reinventar el pasado a modo de restituirle la capacidad de explosión y redención (...) Los partidos políticos de izquierda deberian hoy en Centroamérica tratar de despertar el inconformismo de los vivos con la sociedad actual y consigo mismos evocando el inconformismo de los muertos en las guerras revolucionarias de los años 70 y 80 .

Piquito nos deja un legado, una actitud de vida, una manera auténtica de vivir el compromiso.

En el libro Piquito nos cuenta que el día de su ordenación su hermano le dijo: "has hablado con mucha pasión sobre el sacerdocio al servicio de la gente. Lo único que te pido es que lo cumplas". Creo que lo ha hecho a lo largo de su vida. Este libro es el testimonio de un sacerdote comprometido, de un científico a carta cabal, de una vida de una honestidad sorprendente, en su rol como partícipe de los conflictos de la Provincia, en la fundación del Centro de Investigación y Acción Social (CIAS), haciendo de la Compañía un referente ético que dio esperanzas y confianza a una lucha, trabajando en situaciones de frontera intentando que la política y lo público estuvieran al servicio de los pobres. Su lucha por hacer que la Provincia se inclinara por la liberación como leitmotiv del apostolado social.

Gracias Piquito por este libro que detalla el legado que nos deja su vida y su compromiso. 